\title{
Arc Welding-Laser Shock Forging Process for Improving the Mechanical Properties of the Fe-Cr-C Cladded Layer
}

\author{
Yunpeng Fan, ${ }^{1}$ Chong Zhang, ${ }^{2}$ Hongtao He, ${ }^{1}$ Fengwei Zhang, ${ }^{1}$ and Yongkang Zhang ${ }^{2}$ \\ ${ }^{1}$ Yangjiang High-Tech Investment and Development Co. Ltd, Guangdong Yangjiang High Tech Development Zone 529533, \\ Yangjiang, China \\ ${ }^{2}$ School of Electromechanical Engineering, Guangdong University of Technology, Guangzhou 510006, China
}

Correspondence should be addressed to Yongkang Zhang; zykgdut@163.com

Received 3 August 2021; Accepted 27 October 2021; Published 10 November 2021

Academic Editor: Antonio Riveiro

Copyright (c) 2021 Yunpeng Fan et al. This is an open access article distributed under the Creative Commons Attribution License, which permits unrestricted use, distribution, and reproduction in any medium, provided the original work is properly cited.

\begin{abstract}
While parts can be repaired via arc welding (AW), it is usually necessary to add some types of excitation method to improve the mechanical properties of the cladded layer. Here, the arc welding-laser shock forging (AW-LSF) was used to repair Q235 steel pipes (Fe-Cr-C alloy was used as the cladding material). The effects of the welding current (WC), welding speed (WS), and laser shock frequency (LSF) on the geometry and microhardness of the weld bead were studied. The AW-LSF and AW repair processes were compared. The results demonstrate that the bead width $(W)$ and penetration depth $(D)$ increase with the WC, while the weld height $(H)$ decreases with the WC. The $H, W$, and $D$ all decrease with the WS; $W$ and $D$ increase with the LSF; and $H$ decreases with the LSF. As the WC increases, the hardness of the fusion zone (FZ) and partial fusion zone (PFZ) decreases significantly, while the hardness of the heat-affected zone (HAZ) remains nearly unchanged. As the WS increases, the hardness of the PFZ decreases, while the hardness of the FZ and HAZ remains nearly unchanged. With the increase of the LSF, the hardness of the PFZ, FZ, and HAZ increases. Compared with AW, the AW-LSF can reduce the cladded layer crystal grain size, increase the hardness, and improve the sliding wear resistance.
\end{abstract}

\section{Introduction}

Shafts or tubes are common mechanical parts in industries such as shipbuilding, marine engineering, and offshore wind power. These parts wear or corrode after a period of use, and corresponding measures must be taken to repair them [1]. The use of additive manufacturing technologies to repair parts is a promising field that is gaining increased research attention [2-5].

Arc welding (AW) can be used as an additive manufacturing technology (AMT) to effectively repair damaged parts $[6,7]$. This is classified as a directed energy deposition technology, where a metal wire acts as a material feedstock that is melted by an electric or plasma arc [6]. Commonly used AW technologies include gas metal arc welding (GMAW) [8], gas tungsten arc welding (GTAW) [9], plasma arc welding (PAW) [10], submerged arc welding (SAW) [11], and flux-cored arc welding (FCAM) [12]. Each of these has different features and advantages [13].
AW has the advantage of being able to handle a commercial filler metal because of its associated equipment [14]. AW can be operated outdoors, and there is no limitation on the size of parts that can be repaired [15]. It also has a faster deposition rate, larger bead size, and higher modifiability compared to powder processes, which allows shortening the processing time [16]. In addition, it is possible to minimize material loss by depositing weld beads based on the part [17].

A variety of external excitation methods have been attempted during the cladding process to improve the mechanical properties of the cladded layer, such as electromagnetic stirring [18] and ultrasonic vibration [19]. During cladding, external energy is introduced into the molten pool to cause a series of micro- and macroeffects, which affect the microstructure and mechanical properties of the cladded layer [20]. High-energy lasers can act as the external energy source to generate cavitation and shock waves in the molten pool [21]. These effects improve the mechanical properties of the cladded layer by reducing the 
porosity and refining grains [22]. To date, there have been no relevant research reports using laser shock as the excitation source in AW to repair parts.

This article uses an arc welding-laser shock forging (AWLSF) process to repair Q235 steel pipes (Fe-Cr-C alloy is used as the cladding material). The effects of the welding current, welding speed, and laser shock frequency on the geometry and microhardness of the weld bead are studied. The AW-LSF repair process is compared with the typical AW repair process, and the microhardness, microstructure, and wear properties of the cladded layer are compared to prove the effectiveness of the AW-LSF repair process.

\section{Experimental Procedures}

2.1. Materials. In the experiments, a Q235 steel pipe with an outer diameter of $120 \mathrm{~mm}$ and an inner diameter of $90 \mathrm{~mm}$ was selected as the sample for repair. The YD998 (Fe-Cr-C alloy) welding wire with a diameter of $1.6 \mathrm{~mm}$ was used as the repair material, and the molten layer formed by the welding wire had high hardness and wear resistance. The Q235 and YD998 chemical compositions as provided by the supplier are given in Table 1.

2.2. Arc Welding-Laser Shock Forging. Before the experiment, the Q235 steel pipe was polished with a grinder to remove the surface oxide layer and then wiped with acetone to remove the grease or contaminants on the surface. As shown in Figure 1, a single weld bead was deposited on the surface of the workpiece via AW-LSF (the length of the weld bead was the circumference of the steel pipe), and the weld bead was sampled to measure its geometric morphology and hardness. The angle between the laser beam and the $Y$ direction was $15^{\circ}$, the angle between the welding torch and $Y$ direction was also $15^{\circ}$, and the axis of the welding torch pointed towards the workpiece axis. The workpiece was fixed on the work platform, which controlled the rotation of the workpiece in the $\mathrm{XY}$ plane and the movement along the $Z$ direction. The LINKEN-NBC-500A model was used for the electric welding machine, the voltage was set to $34 \mathrm{~V}$, the wire feeding rate was $25 \mathrm{~mm} / \mathrm{s}$, and the shielding gas (the pressure was $6 \mathrm{MPa}$ and the flow rate was $0.25 \mathrm{~L} / \mathrm{s}$ ) was a 95:5 mixture of argon and carbon dioxide. The laser was selfdeveloped and in solid state with the main technical parameters: a wavelength of $1064 \mathrm{~nm}$, pulse width of $6 \mathrm{~ns}$, frequency of $1-10 \mathrm{~Hz}$, energy of $1 \mathrm{~J}$, and spot diameter of $4 \mathrm{~mm}$. As shown in Table 2, single-factor experiments were first used to study the effects of the welding current, welding speed, and laser shock frequency on the geometric characteristics and microhardness of the weld. Experiments were then performed based on the optimal parameters of the single-factor experiments to compare the hardness, microstructure, and wear properties of the cladded layer obtained by both AW-LSF and AW.

\subsection{Macroscopic Morphology and Microstructure} Characterization. After the AW-LSF, the parts were cooled to room temperature, and the surface morphology of the weld bead was collected with an industrial camera (IMPERX ICL-B2000, USA). Wire cutting was used to sample the weld bead area formed by a stable arc, and the sample size was $30 \mathrm{~mm} \times 30 \mathrm{~mm} \times 25 \mathrm{~mm}$, as shown in Figure 2(a). All samples were ultrasonically cleaned in acetone solution to remove oil stains on the surface. The sample was then mounted, grounded, and polished until the surface had a mirror finish. Finally, a $4 \%$ nitric acid ethanol solution was used to etch the sample surface, as shown in Figure 2(b). An industrial camera was used to observe the cross-sectional profile of the weld bead, and a desktop scanning electron microscope (SEM, Hitachi TM3030, Japan) was used to observe the microstructure of the weld bead.

2.4. Hardness Test. As shown in Figure 3, a Vickers hardness tester (HXD-1000TMC/LCD, China) was used under a load of $500 \mathrm{~g}(4.9 \mathrm{~N})$ for $15 \mathrm{~s}$ to measure the Vickers low-force hardness of the sample weld beads along the FZ, PFZ, HAZ, and BM (ISO 6507-1:2018 test standard). A total of 18 test points were selected for each sample. To ensure testing accuracy, each additional test point was added to the left and right parallel positions of each of the 18 selected points, and the average of the three points was taken as the result of each test point.

2.5. Wear Performance Test. A reciprocating friction and wear tester (MSR-2T, China) was used to evaluate the wear resistance of the sample. The size of the sample used for the test was $20 \mathrm{~mm} \times 20 \mathrm{~mm} \times 3 \mathrm{~mm}$. The samples were grounded and polished before the wear tests. A YG6 bearing steel ball with a diameter of $6 \mathrm{~mm}$ was used as the reverse of the sample fixed on the turntable. The axial wear load was set to $500 \mathrm{~g}(4.9 \mathrm{~N})$, the wheel speed was $100 \mathrm{r} / \mathrm{min}(1.66 \mathrm{r} / \mathrm{s})$, and the reciprocating sliding length was $10 \mathrm{~mm}$ with a total test time of $15 \mathrm{~min}$. A laser scanning confocal microscope (Olympus OLS4100, Japan) was used to measure the width, depth, and cross-sectional area for the grinding mark to compare the wear resistance.

\section{Results and Discussion}

3.1. Effects of the AW-LSF Parameters on the Weld Morphology. An industrial camera was used to observe and measure the weld bead surface and cross section morphology to study the influence of the AW-LSF parameters. Figure 4(a) shows a macrophotograph of the weld bead section formed via AW-LSF. The geometric characteristics of the weld bead include the weld height $(H)$, bead width $(W)$, and penetration depth $(D)$. Two shape coefficients of the aspect ratio $(A R)$ and residual coefficient (RC) better describe the shape characteristics of a single weld bead. The AR and $\mathrm{RC}$ are unitless characteristics and are defined by equations (1) and (2), respectively.

$$
\begin{aligned}
& \mathrm{AR}=\frac{D}{W}, \\
& \mathrm{RC}=\frac{H}{W} .
\end{aligned}
$$


TABLe 1: Chemical compositions of Q235 and YD998 (wt.\%).

\begin{tabular}{lcccccccc}
\hline Element & $\mathrm{C}$ & $\mathrm{Cr}$ & $\mathrm{Mn}$ & $\mathrm{Si}$ & $\mathrm{Ni}$ & $\mathrm{S}$ & $\mathrm{P}$ & $\mathrm{Fe}$ \\
\hline YD998 & 4.6 & 24 & 1.2 & 0.7 & 0.46 & 0.003 & 0.003 \\
Q235 & 0.17 & - & 0.44 & 0.18 & - & 0.045 & 0.017 & Balance \\
\hline
\end{tabular}

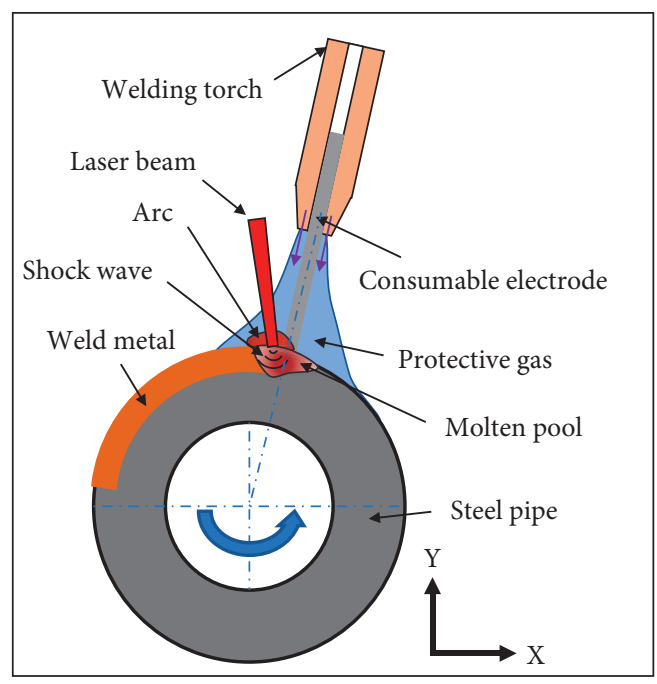

(a)

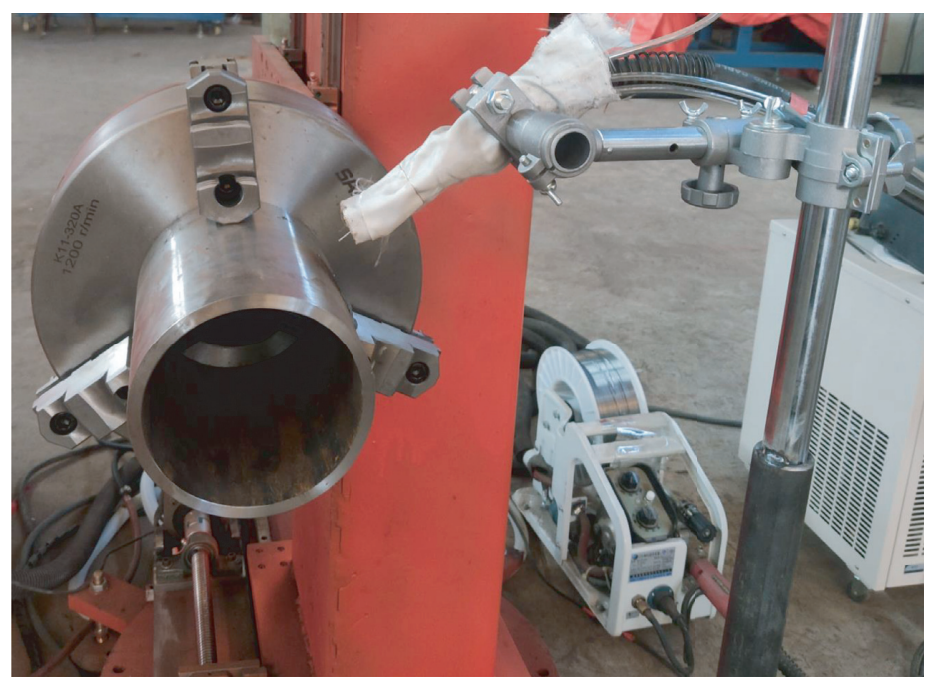

(b)

FIgUre 1: Arc welding-laser shock forging (AW-LSF) process setup. (a) Schematic view and (b) actual setup.

TABLE 2: AW-LSF process parameters and levels.

\begin{tabular}{lcc}
\hline Welding current $(\mathrm{A})$ & Cladding speed $(\mathrm{mm} / \mathrm{min})$ & Laser shock frequency $(\mathrm{Hz})$ \\
\hline $80-200$ & 140 & 2 \\
130 & $80-240$ & 2 \\
130 & 160 & $2-10$ \\
\hline
\end{tabular}

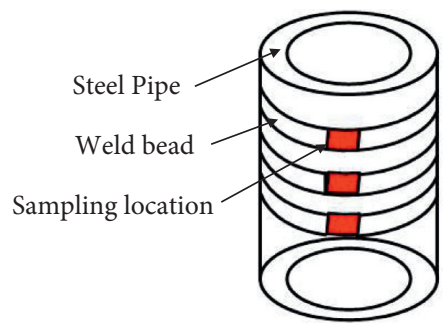

(a)

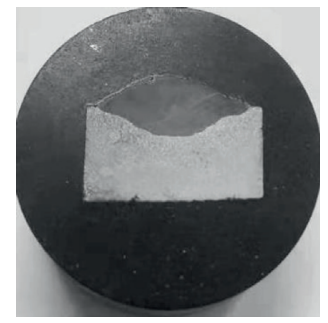

(b)

Figure 2: (a) Schematic diagram of the sampling location. (b) Digital photo of the sample after etching.

Figure 4(b) shows the influence of the welding current on the $H, W, D, A R$, and RC. When other parameters are held constant, $W, D$, and AR increase with the welding current, while $H$ and RC decrease with the welding current. The reasons are as follows: a larger welding current gives rise to a larger molten pool, which makes $W$ and $D$ increase with the welding current; a larger welding current makes the welding wire melt more fully, and the molten metal flows more fully in the molten pool, which makes $H$ decrease with the welding current. As shown in Figure 5(a), for small welding currents, the welding wire does not completely melt, which results in an uneven distribution of the weld bead surface, and a "hump phenomenon" appears. As the current increases, the uniformity of the weld bead surface is improved, and the weld bead surface appears as regular "fish scales." When the current is too large, the arc is unstable so that the gas in the molten pool cannot be discharged in time, which results in pores in the weld bead.

Figure 4(c) shows the effects of the welding speed on the $H$, $W, D, \mathrm{AR}$, and RC. When other parameters are held constant, the $H, W, D, \mathrm{AR}$, and RC all decrease with the welding speed. The reasons are as follows: a higher welding speed brings about a smaller molten pool, which makes $W$ and $D$ decrease with the welding speed; a higher welding speed results in lesser molten 


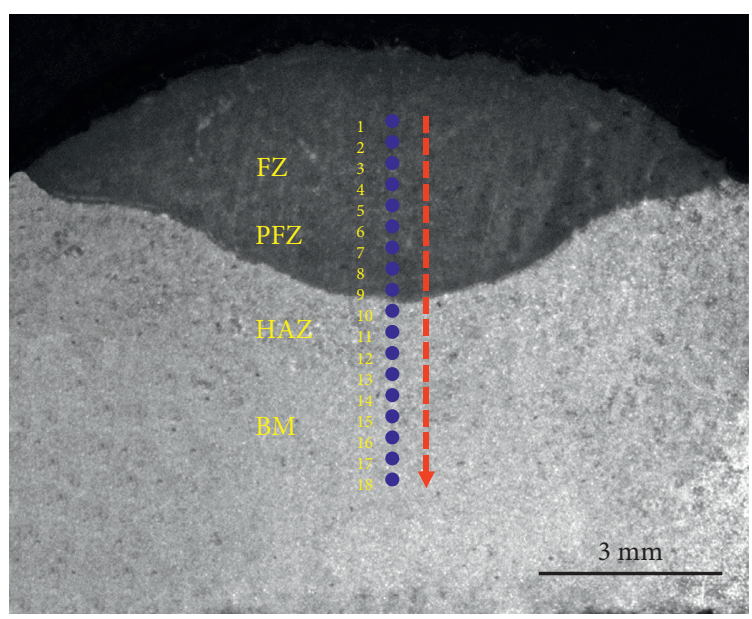

Figure 3: Microhardness mapping along the fusion zone (FZ), partial fusion zone (PFZ), heat-affected zone (HAZ), and base material (BM) of a typical weld prepared by the AW-LSF (welding current of $130 \mathrm{~A}$, welding speed of $160 \mathrm{~mm} / \mathrm{min}$, and laser shock frequency of $4 \mathrm{~Hz}$ ).

metal in the molten pool, which makes $H$ decrease with the welding speed. As shown in Figure 5(b), at low-welding speeds, excessive welding energy forms an excessively large molten pool. The molten pool flows under the action of gravity, making the surface of the weld bead uneven and resulting in "weld beads." As the speed increases, the welding energy decreases; thus, the formed molten pool becomes moderate, and the weld bead flattens and evens. When the speed is too high, the welding energy is too small, and the molten metal cannot completely fill the molten pool. This significantly narrows the width of the weld bead, the surface of the weld bead becomes discontinuous, and a significant "undercut phenomenon" occurs.

Figure 4(d) shows the effects of the laser shock frequency on $H, W, D, \mathrm{AR}$, and $\mathrm{RC}$. When the other parameters are held constant, $W, D$, and AR increase with the laser shock frequency, while $H$ and RC decrease with the laser shock frequency. The reasons are as follows: a higher laser shock frequency makes the shock wave stimulate the molten pool more intensively, and the faster flow of the molten metal makes the heat in the molten pool diffuse faster to the surroundings, thereby forming a larger molten pool, which makes $W$ and $D$ increase with the laser shock frequency; a greater laser impact frequency leads to a more full flow of the molten metal, which makes $H$ decrease with the laser shock frequency. As shown in Figure 5(c), when the laser shock frequency is low, the weld bead surface is relatively flat, but the weld bead distribution is nonuniform. As the frequency increases, the surface of the weld bead becomes even and flat and shows regular "fish scales." This is because small laser frequencies provide a longer time interval for the laser to act on the molten pool. Thus, the shock wave generated by the laser does not continuously excite the molten pool, which causes the pool to have an irregular flow and results in an uneven weld bead distribution. The time interval of the laser acting on the molten pool at larger frequencies decreases, and the shock wave generated by the laser continuously excites the molten pool so that it has a regular flow. This leads to an even distribution for the weld bead.

\subsection{Effects of the AW-LSF Parameters on the Hardness.} Vickers microhardness tests were performed to evaluate the effects of the AW-LSF process parameters on the hardness. Figure 6 shows the influence of the AW-LSF parameters on the hardness distribution of the weld bead for the FZ, PFZ, $\mathrm{HAZ}$, and BM. The hardness of the FZ was the largest $(>450$ HV0.5), and the hardness of the PFZ was greatly reduced (drop reached $250 \mathrm{HV} 0.5$ ). Compared with the PFZ, the hardness of the HAZ also had a large decrease (drop reached $50 \mathrm{HV} 0.5$ ), while the hardness of the BM was the smallest (approximately $169 \mathrm{HV} 0.5$ ). As shown in Figure 6(a), when the current was $130 \mathrm{~A}$, the average hardness of the FZ, PFZ, and HAZ was 560, 334, and 188 HV0.5, respectively, and when the current was $180 \mathrm{~A}$, the average hardness was 477 , 236, and 184 HV0.5. This shows that, as the current increases, the increased heat input causes the hardness of the FZ and PFZ to decrease, which is consistent with the results of previous studies [23].

As shown in Figure 6(b), when the welding speed was $120 \mathrm{~mm} / \mathrm{min}$, the average hardness of the FZ, PFZ, and HAZ was 539, 319, and 209 HV0.5, respectively, and when the welding speed was $200 \mathrm{~mm} / \mathrm{min}$, the average hardness was 541, 276, and 208 HV0.5. This shows that, as the welding speed increases, the hardness of PFZ decreases, while the hardness of the FZ and HAZ remains nearly unchanged. As shown in Figure 6(c), when the laser shock frequency was $5 \mathrm{~Hz}$, the average hardness of the FZ, PFZ, and HAZ was 568, 285, and $187 \mathrm{HV0.5}$, respectively, and when the laser shock frequency was $10 \mathrm{~Hz}$, the average hardness was 618, 339, and $213 \mathrm{HV} 0.5$. This shows that, as the frequency of laser shock increases, the hardness of the PFZ, FZ, and HAZ also increases. This is consistent with the results of previous studies [24]. 


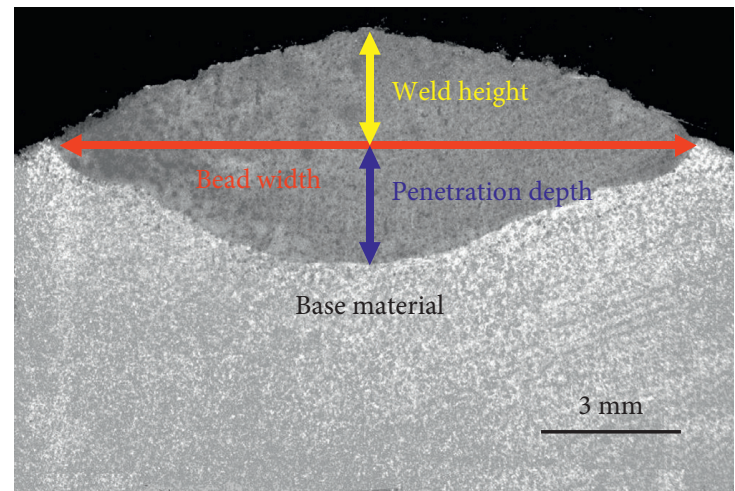

(a)

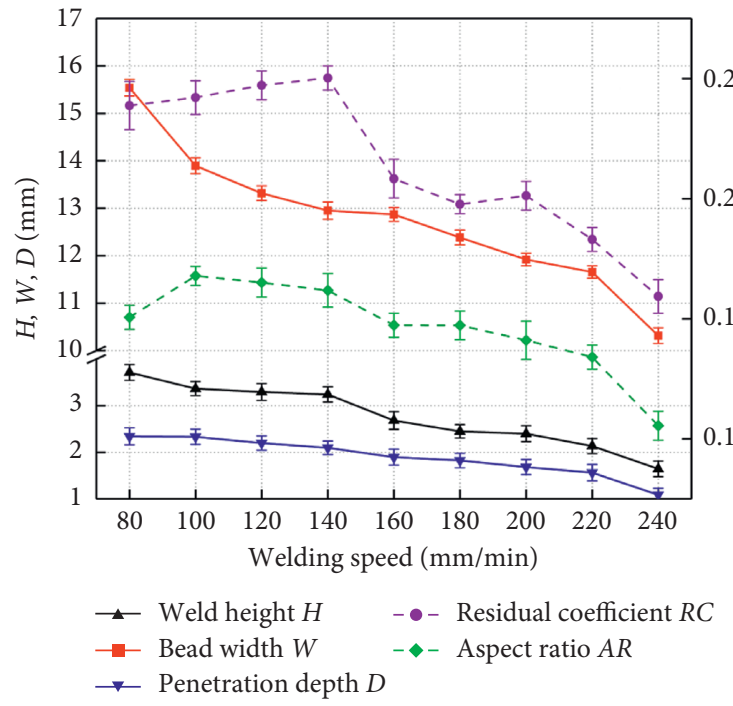

(c)

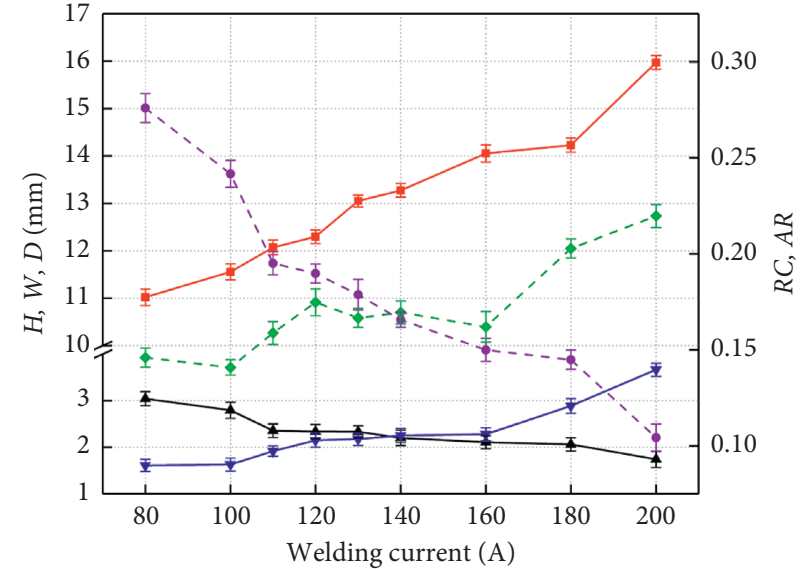

$\leftarrow$ Weld height $H \quad-\bullet$ - Residual coefficient $R C$
$\rightarrow$ Bead width $W \quad-\bullet-$ Aspect ratio $A R$
$\rightarrow$ Penetration depth $D$

(b)

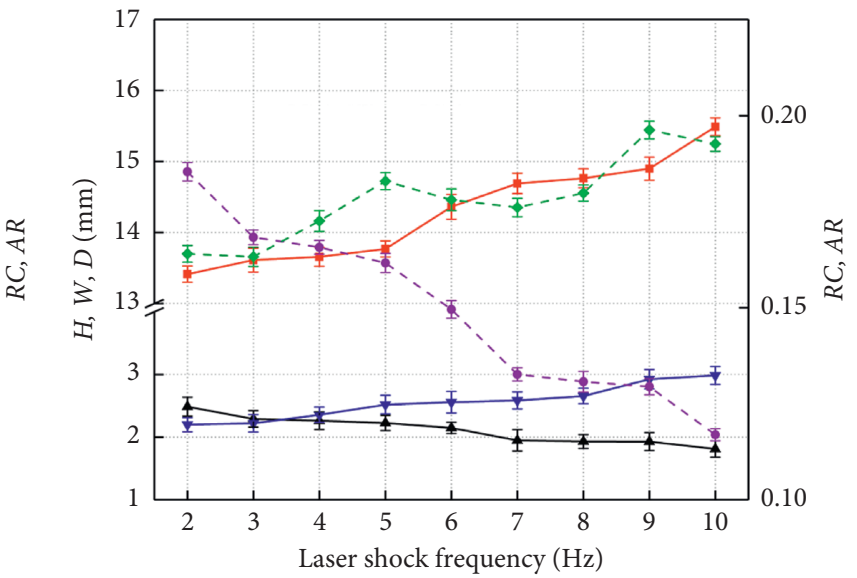

$\leftarrow$ Weld height $H \quad-\bullet$ - Residual coefficient $R C$
$\rightarrow$ Bead width $W \quad-\bullet-$ Aspect ratio $A R$
$\rightarrow$ Penetration depth $D$

(d)

Figure 4: (a) Optical macrograph of the Q235 steel pipe welded via AW-LSF (welding current of $110 \mathrm{~A}$, welding speed of $140 \mathrm{~mm} / \mathrm{min}$, and laser shock frequency of $2 \mathrm{~Hz}$ ), which illustrates the geometric characteristics. (b-d) Effects of the AW-LSF parameters on the weld height $(H)$, bead width $(W)$, penetration depth $(D)$, aspect ratio (AR), and residual coefficient (RC). (b) Welding current. (c) Welding speed. (d) Laser shock frequency.

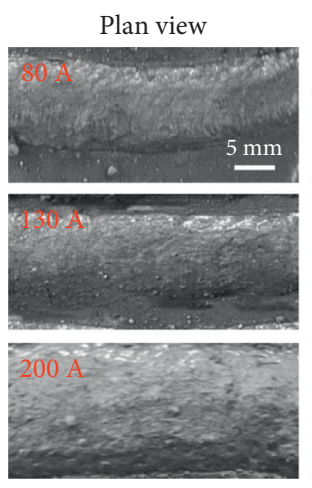

(a)
Section view
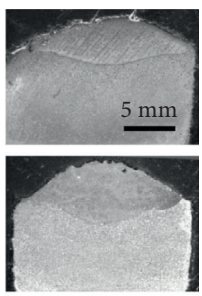

4

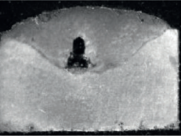

Figure 5: Digital photos of the Q235 steel pipe cladded by the AW-LSF.
Section view
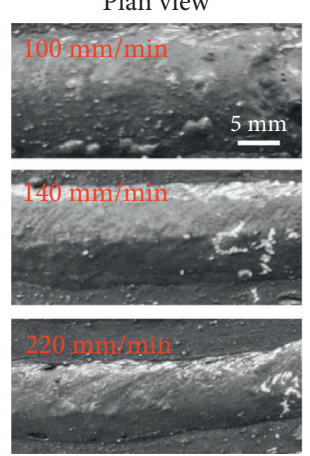

(b)
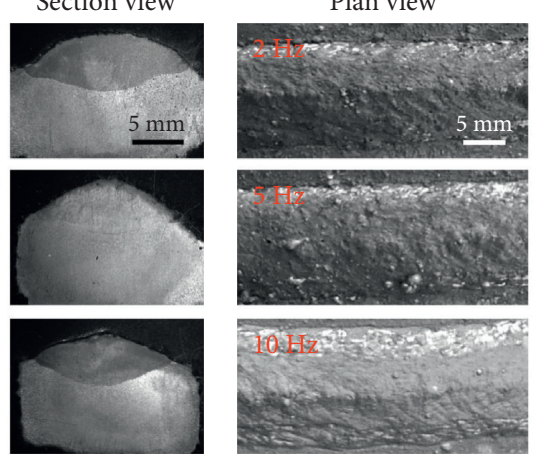

(c)
Section view

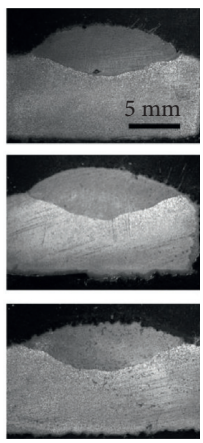




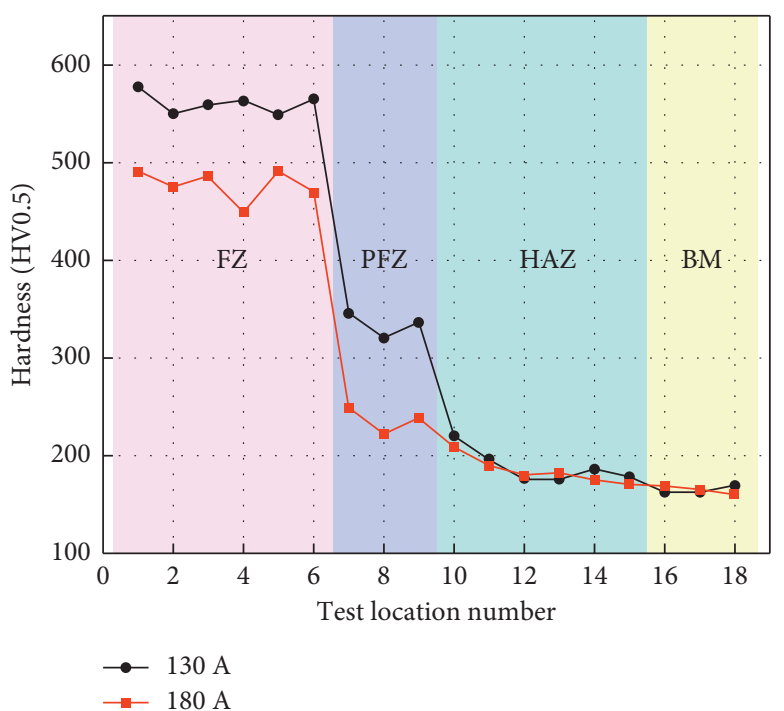

(a)

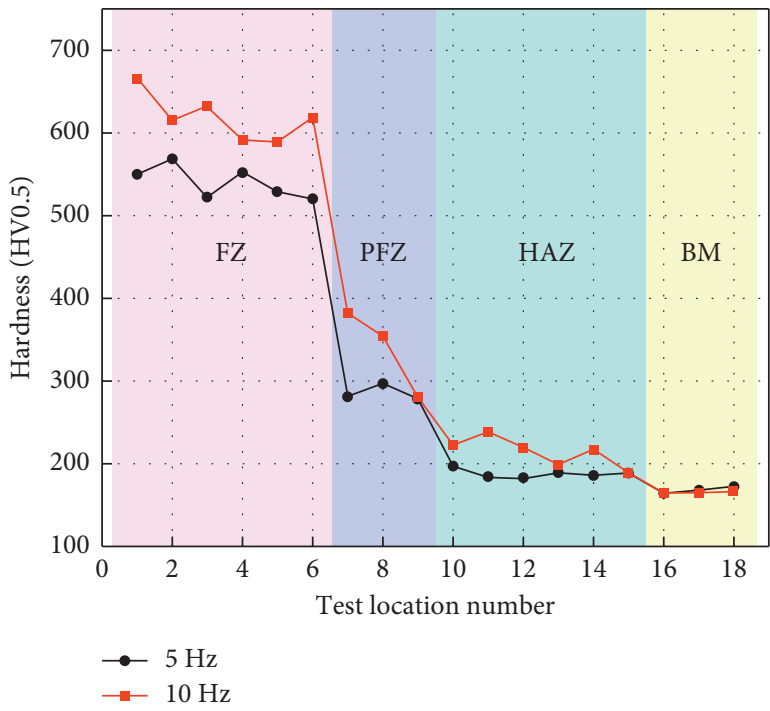

(c)

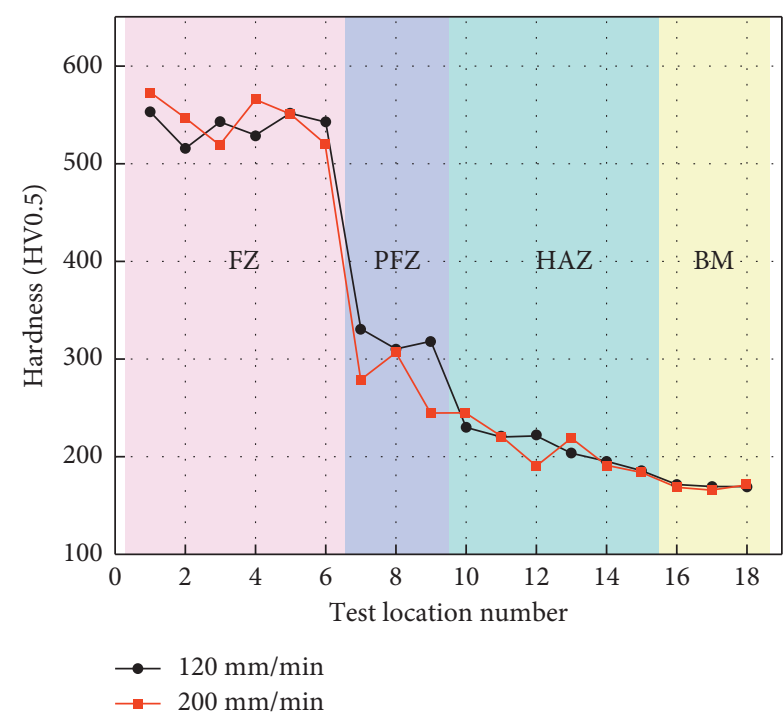

(b)

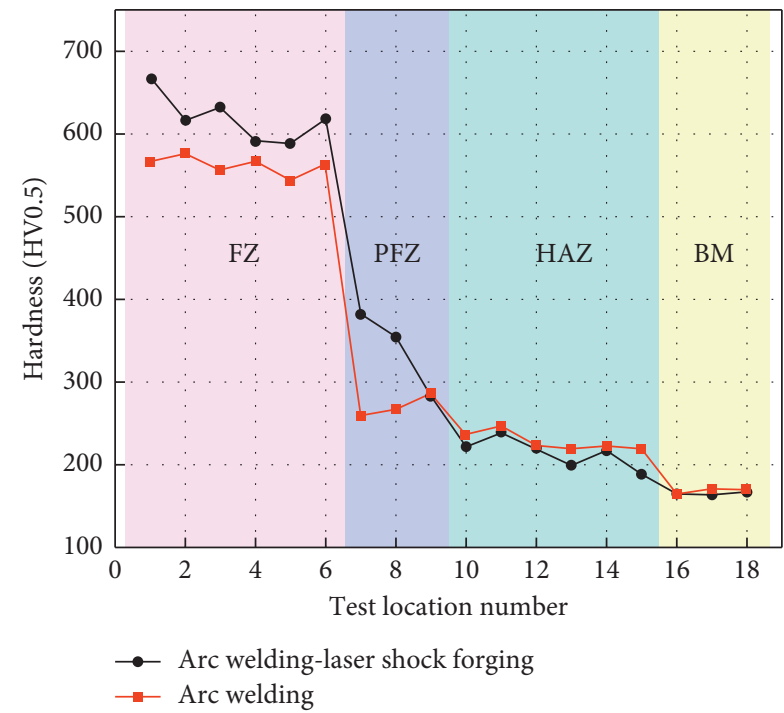

(d)

FIGURE 6: $(\mathrm{a}-\mathrm{c})$ Effects of AW-LSF parameters on the hardness profiles of the weld beads for FZ, PFZ, HAZ, and BM. (a) Welding current. (b) Welding speed. (c) Laser shock frequency. (d) Hardness distribution profile of the weld seam of the AW (welding current is $130 \mathrm{~A}$, and welding speed is $140 \mathrm{~mm} / \mathrm{min}$ ) and the AW-LSF (welding current is $130 \mathrm{~A}$, welding speed is $140 \mathrm{~mm} / \mathrm{min}$, and laser shock frequency is $10 \mathrm{~Hz}$ ).

\subsection{Comparison of Arc Welding and Arc Welding-Laser Shock Forging}

3.3.1. Microstructure and Hardness. To prove the effectiveness of the AW-LSF, the hardness and microstructure of the formed cladded layer (welding current of $130 \mathrm{~A}$, welding speed of $140 \mathrm{~mm} / \mathrm{min}$, and laser shock frequency of $10 \mathrm{~Hz}$ ) and AW (welding current of $130 \mathrm{~A}$ and welding speed of $140 \mathrm{~mm} / \mathrm{min}$ ) were compared. From Figure 6(d), the average hardness from the AW for the FZ, PFZ, and HAZ was 561, 267 , and $216 \mathrm{HV} 0.5$, respectively, and was 618,339 , and 213 HV0.5 for the AW-LSF. Compared with the AW, the hardness in the FZ for the AW-LSF sample increased by approximately $10 \%$, the PFZ increased by $\sim 29 \%$, and the
HAZ remained nearly the same. Thus, the AW-LSF can effectively increase the hardness of the cladded layer.

From Figure $7(\mathrm{a})$, when using the AW, the grains in the FZ are relatively coarse and composed primarily of acicular martensite and granular bainite. From Figure 7(b), when using the AW-LSF, the metallographic structure of the FZ is strongly refined, which is composed primarily of a large (small) amount of lath (acicular) martensite. This is because the coarse dendrites that initially formed in the fusion zone will break due to the laser shock wave to form fine dendrites. These fine dendrites diffuse to various areas of the molten pool with the metal liquid flow, thereby refining the crystal grains. Grain refinement increases the number of grain boundaries. This leads to a greater resistance of the material 


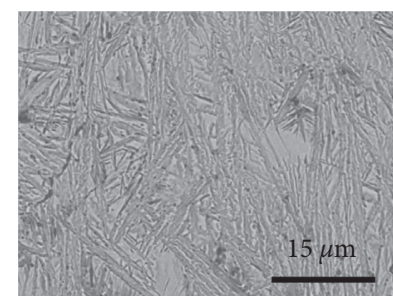

(a)

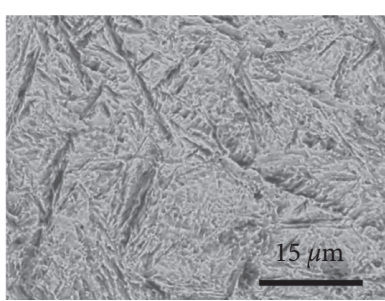

(b)

Figure 7: SEM images of the microstructure of the fusion zone: (a) AW and (b) AW-LSF.

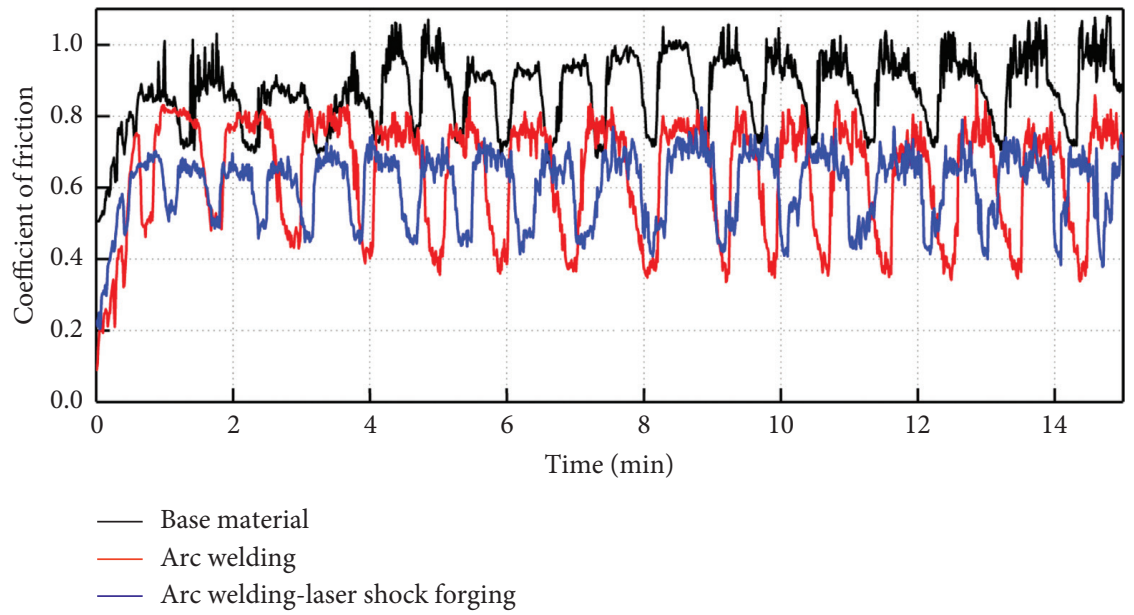

Figure 8: Evolution of friction coefficient of the BM, AW cladded layer, and AW-LSF cladded layer as a function of wear time.

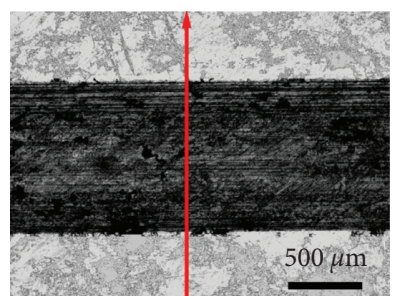

(a)

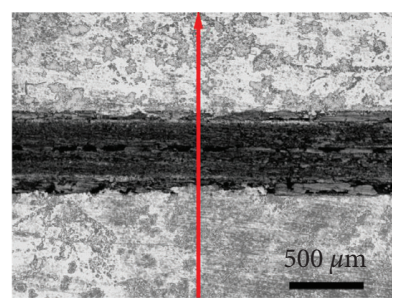

(b)

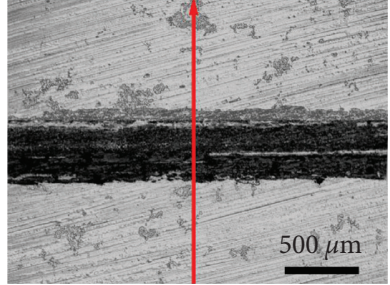

(c)

Figure 9: Micrographs of the grinding mark: (a) BM, (b) AW cladded layer, and (c) AW-LSF cladded layer.

to dislocation movements and a stronger ability to resist plastic deformation, which is manifested as an increased hardness $[25,26]$.

3.3.2. Wear Performance Test. A wear performance test was performed to study the wear resistance of the cladded layer formed from the AW-LSF. In Figure 8, the average friction coefficients of the base material, AW cladded layer, and AWLSF cladded layer are $0.87,0.64$, and 0.61 , respectively. Compared with the base material and AW cladded layer, the average friction coefficient of the AW-LSF cladded layer is reduced by $30 \%$ and $5 \%$, respectively. This is because, compared with the AW cladded layer, the laser shock enhances the hardness of the cladded layer, thereby reducing the contact surface between the bearing steel ball and the cladded layer, which makes the friction coefficient of the AW-LSF cladded layer smaller.

Figure 9 shows the micrographs of the grinding mark under different conditions. It can be seen that there is a "furrow phenomenon" in the grinding mark caused by abrasive wear, and an unworn area in the grinding marks of the AW-LSF cladded layer exists. Figure 10 shows the crosssectional profiles of the grinding mark under different conditions. Measured geometric parameters using a laser scanning confocal microscope were: the depth, width, and cross-sectional area of the grinding mark. Figure 11(a) shows the geometric dimensions of the grinding mark under different conditions. The grinding mark depths of the AWLSF cladded layer, AW cladded layer, and the base material were $4.079,10.833$, and $36.346 \mu \mathrm{m}$, and the widths were $348.95,428.71$, and $1011.954 \mu \mathrm{m}$, respectively. The grinding 


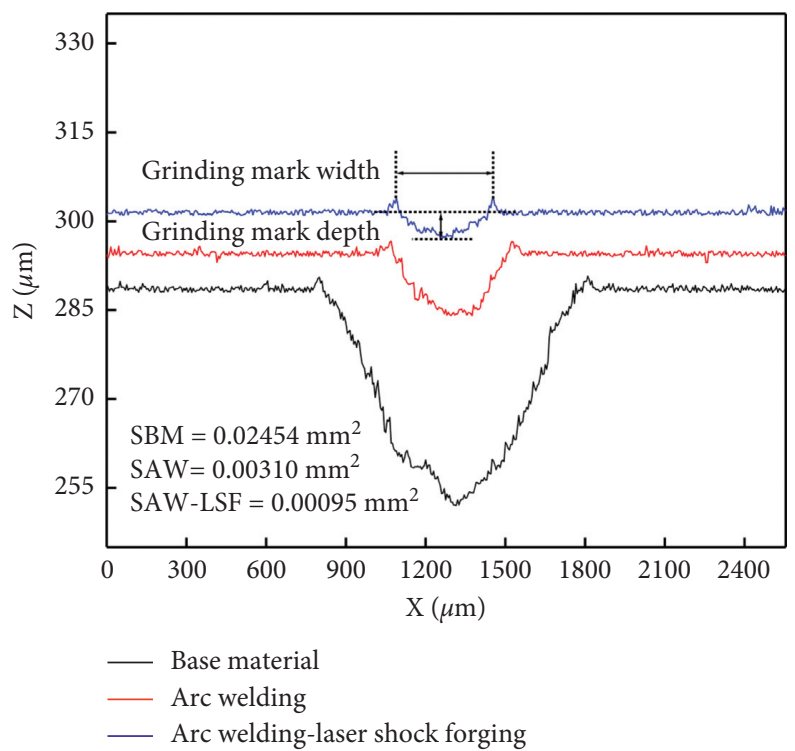

FIGURE 10: The cross-sectional profile of the grinding marks measured along the red lines is marked in Figure 9. Grinding mark width: distance between the highest point of the two rims. Grinding mark depth: distance between the surface of the substrate and the lowest point of the grinding mark. The SBM, SAW, and SAW-LSF are the cross-sectional areas of the grinding mark formed by the BM, the AW cladded layer, and the AW-LSF cladded layer, respectively.

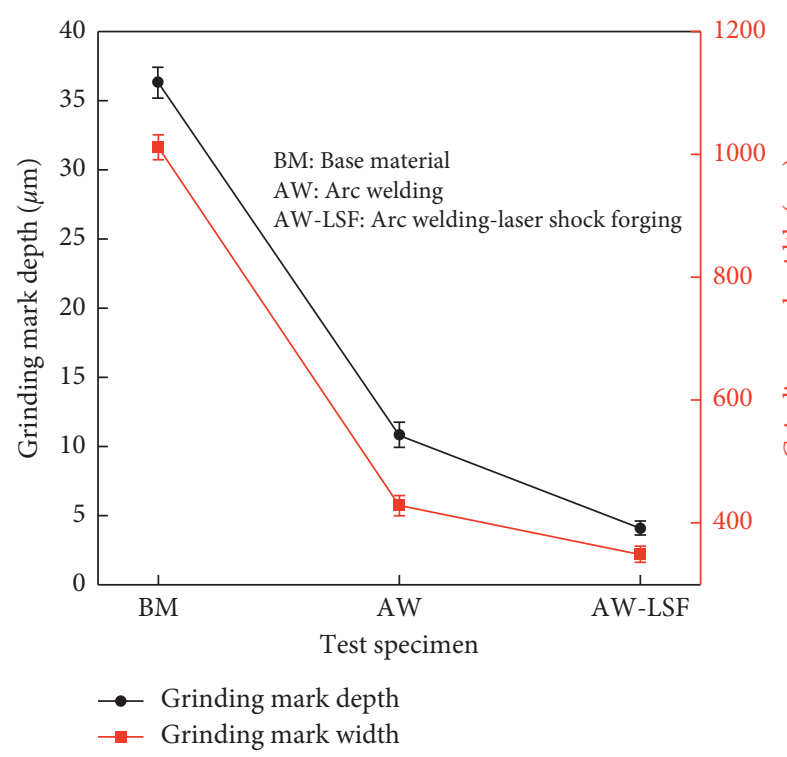

(a)

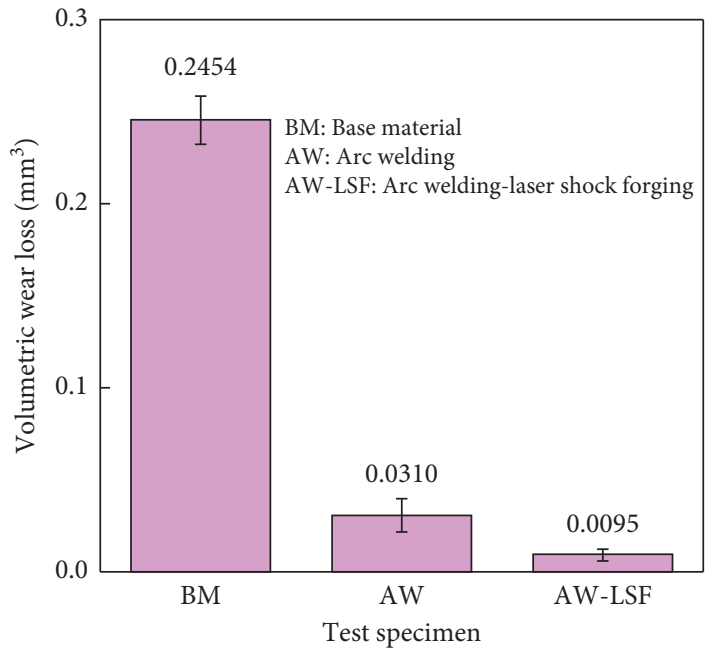

(b)

FigURE 11: Wear characteristics of the BM, AW cladded layer, and AW-LSF cladded layer: (a) width and depth of the grinding mark and (b) volumetric wear loss. Volumetric wear loss $=$ cross-sectional area of the grinding mark $\times$ reciprocating sliding length.

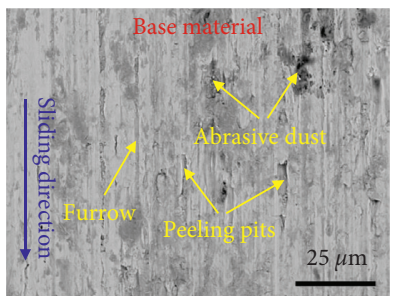

(a)

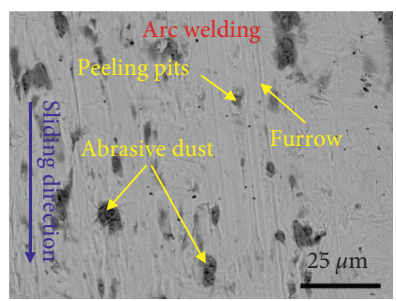

(b)

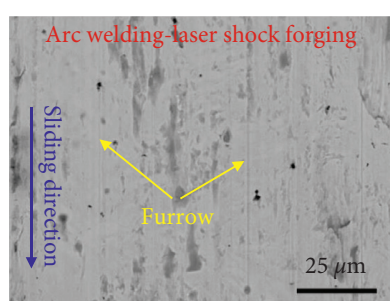

(c)

FIgURE 12: SEM images of the worn surface of the sample: (a) BM, (b) AW cladded layer, and (c) AW-LSF cladded layer. 


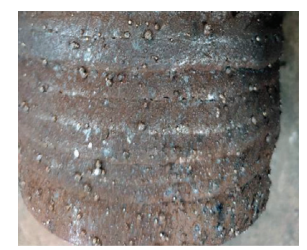

(a)

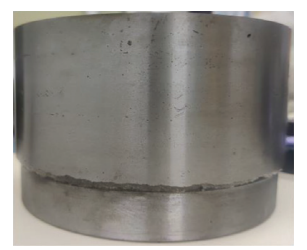

(b)

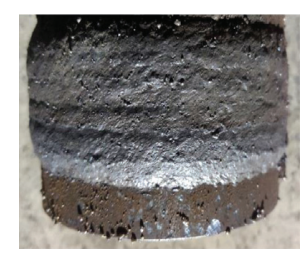

(c)

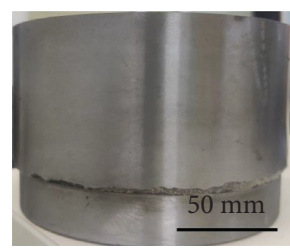

(d)

FIGURE 13: Digital photos of the Q235 steel pipe after ( $a, b)$ cladding; $(c, d)$ partially cladded layer is removed by turning (a, c) AW and (b, d) AW-LSF.

mark of the base material zone was the widest, and that of the AW-LSF cladded layer was the narrowest. Figure 11(b) shows the volumetric wear loss of the sample under different conditions. The volume wear loss of the AW-LSF cladded layer, AW cladded layer, and base material was 0.0095 , 0.0310 , and $0.2454 \mathrm{~mm}^{3}$, respectively. This indicates that the AW-LSF cladded layer has the best antiwear performance. Therefore, the AW-LSF can effectively improve the wear resistance of the cladded layer.

Figure 12 shows SEM images of the worn surface under different conditions. Figure 12(a) shows that the wear surface of the base material has deep and wide furrows, a large amount of abrasive dust, and a large area of peeling pits. The wear mechanism is primarily adhesive and contact fatigue wear. Figure 12(b) shows that the wear surface of the AW cladded layer has shallow furrows and a small amount of abrasive dust with more peeling pits; the wear mechanism is mostly contact fatigue wear. Figure 12(c) shows that the wear surface of the AW-LSF cladded layer only has shallow and narrow furrows with a large furrow spacing, and there is no obvious fatigue peeling pits or abrasive dust accumulation. This indicates that the AWLSF can increase the fatigue resistance of the cladded layer to a certain extent. This is because laser shock can bring about residual compressive stress in the cladded layer, and the grain refinement caused by laser shock can increase the hardness and toughness of the cladded layer, thereby effectively improving the fatigue resistance of the cladded layer [27].

3.3.3. Macroscopic Appearance of the Overall Restoration. From Figures 13(a) and 13(c), after the overall repair of the steel pipe using the AW, the distribution of the cladded layer on the surface of the workpiece was relatively uniform, but there were more spatters and pores on the surface of the cladded layer. After removing the part of the cladded layer, a few small pores were observed on the surface of the restoration. Figures 13(b) and 13(d) show that, after the steel pipe is fully repaired by the AW-LSF, the cladded layer was smooth and flat with only a few small spatters and no obvious pores. After removing part of the cladded layer, there were no obvious defects on the surface of the repaired part. This shows that the AW-LSF can be effectively used to repair steel pipes.

\section{Conclusions}

In this study, the AW-LSF process was used to repair a steel pipe. The conclusions are as follows:

(1) The $W, D$, and AR increase with the welding current; $H$ and RC decrease with the welding current; $H, W$, $D, \mathrm{AR}$, and RC all decrease with the welding speed; $W, D$, and AR increase with the laser shock frequency; $H$ and $\mathrm{RC}$ decrease with the laser shock frequency.

(2) As the welding current increases, the hardness of the FZ and PFZ decreases significantly, while the hardness of the HAZ remains nearly unchanged. As the welding speed increases, the hardness of the PFZ decreases, while those of the FZ and HAZ remain nearly unchanged. With the increase of the laser shock frequency, the hardness of the PFZ, FZ, and HAZ increases.

(3) Compared with the AW repair process, the AW-LSF can reduce the grain size of the cladded layer and give a better wear resistance. It increases the hardness of the FZ by approximately $10 \%$, increases the hardness of the PFZ by about 29\%, and reduces the friction coefficient by around $5 \%$.

\section{Data Availability}

The data used to support the findings of this study are included within the article.

\section{Conflicts of Interest}

The authors declare no conflicts of interest.

\section{Authors' Contributions}

Yunpeng Fan conceptualized the study, contributed to methodology, investigated the study, and reviewed and edited the manuscript. Chong Zhang validated the study and wrote the original draft. Hongtao He and Fengwei Zhang validated the study and reviewed and edited the manuscript. Yongkang Zhang supervised the study and provided resources. All authors read and approved the manuscript. 


\section{Acknowledgments}

This work was financially supported by the Project from Department of Natural Resources of Guangdong Province ([2019] no. 052; project no.: gdoe [2019] no. A12)

\section{References}

[1] L. R. Huang, Z. Z. He, and Z. Liu, "Repair technology of shafts in boats and ships," Advanced Materials Research, vol. 602-604, pp. 1609-1612, 2013.

[2] C. Guo, S. Liu, R. Hu, C. Liu, and F. Chen, "Microstructure and properties of a $2.25 \mathrm{Cr} 1 \mathrm{Mo} 0.25 \mathrm{~V}$ heat-resistant steel produced by wire arc additive manufacturing," Advances in Materials Science and Engineering, vol. 2020, Article ID 8470738, 9 pages, 2020.

[3] R. A. Rahman Rashid, C. J. Barr, S. Palanisamy et al., "Effect of clad orientation on the mechanical properties of laser-clad repaired ultra-high strength $300 \mathrm{M}$ steel," Surface and Coatings Technology, vol. 380, Article ID 125090, 2019.

[4] Y. Zhu, Y. Yang, X. Mu, W. Wang, Z. Yao, and H. Yang, "Study on wear and RCF performance of repaired damage railway wheels: assessing laser cladding to repair local defects on wheels," Wear, vol. 430-431, pp. 126-136, 2019.

[5] Z. Zhao, J. Chen, Q. Zhang, H. Tan, X. Lin, and W.-d. Huang, "Microstructure and mechanical properties of laser additive repaired Ti17 titanium alloy," Transactions of Nonferrous Metals Society of China, vol. 27, no. 12, pp. 2613-2621, 2017.

[6] V. Negi and S. Chattopadhyaya, "Critical assessment of temperature distribution in submerged arc welding process," Advances in Materials Science and Engineering, vol. 2013, Article ID 543594, 9 pages, 2013.

[7] W. Xie, C. Fan, C. Yang, and S. Lin, "Effect of acoustic field parameters on arc acoustic binding during ultrasonic waveassisted arc welding," Ultrasonics Sonochemistry, vol. 29, pp. 476-484, 2016.

[8] P. Kah, R. Suoranta, and J. Martikainen, "Advanced gas metal arc welding processes," International Journal of Advanced Manufacturing Technology, vol. 67, no. 1-4, pp. 655-674, 2013.

[9] S. Fujiyama, M. Shigeta, and M. Tanaka, "Comparison between methods measuring arc efficiency of gas tungsten arc welding," Science and Technology of Welding \& Joining, vol. 26, no. 5, pp. 371-376, 2021.

[10] J. Wilden, J. P. Bergmann, and H. Frank, "Plasma transferred arc welding-modeling and experimental optimization," Journal of Thermal Spray Technology, vol. 15, no. 4, pp. 779-784, 2006.

[11] S. Dong, Y. Han, C. Jia et al., "Organic adhesive assisted underwater submerged-arc welding," Journal of Materials Processing Technology, vol. 284, Article ID 116739, 2020.

[12] M. Abbas, A. S. Hamdy, and E. Ahmed, "The comparison of gas tungsten arc welding and flux cored arc welding effects on dual phase steel," Materials Research Express, vol. 7, no. 3, Article ID 036523, 2020.

[13] A. IvánTabernero, A. Paskual, P. Álvarez, and A. Suárez, "Study on arc welding processes for high deposition rate additive manufacturing," Procedia CIRP, vol. 68, pp. 358-362, 2018.

[14] B. Wang, X.-M. Zhu, H.-C. Zhang, H.-T. Zhang, and J.-C. Feng, "Characteristics of welding and arc pressure in the plasma-tig coupled arc welding process," Metals, vol. 8, no. 7, pp. 512-513, 2018.
[15] G. Casalino and M. Mortello, "Laser-arc combined welding of aa5754 alloy," Materials Letters, vol. 284, Article ID 128946, 2021.

[16] L. C. Hwa, S. Rajoo, A. M. Noor, N. Ahmad, and M. B. Uday, "Recent advances in 3D printing of porous ceramics: a review," Current Opinion in Solid State \& Materials Science, vol. 21, no. 6, pp. 323-347, 2017.

[17] A. Ikram and H. Chung, "Numerical simulation of arc, metal transfer and its impingement on weld pool in variable polarity gas metal arc welding," Journal of Manufacturing Processes, vol. 64, pp. 1529-1543, 2021.

[18] Y.-l. Bai, J. Xu, Z.-f. Zhang, and L.-k. Shi, "Annulus electromagnetic stirring for preparing semisolid A357 aluminum alloy slurry," Transactions of Nonferrous Metals Society of China, vol. 19, no. 5, pp. 1104-1109, 2009.

[19] S. Kumar, C. S. Wu, G. K. Padhy, and W. Ding, "Application of ultrasonic vibrations in welding and metal processing: a status review," Journal of Manufacturing Processes, vol. 26, pp. 295-322, 2017.

[20] Q. Chen, S. Lin, C. Yang, C. Fan, and H. Ge, "Grain fragmentation in ultrasonic-assisted TIG weld of pure aluminum," Ultrasonics Sonochemistry, vol. 39, pp. 403-413, 2017.

[21] S. Gacek and X. Wang, "Dynamics evolution of shock waves in laser-material interaction," Applied Physics A, vol. 94, no. 3, pp. 675-690, 2009.

[22] J. Ciganovic, S. Zivkovic, M. Momcilovic et al., "Laser-induced features at titanium implant surface in vacuum ambience," Optical and Quantum Electronics, vol. 48, no. 2, pp. 1-8, 2016.

[23] D. Min, J. Shen, S. Lai, and J. Chen, "Effect of heat input on the microstructure and mechanical properties of tungsten inert gas arc butt-welded AZ61 magnesium alloy plates," Materials Characterization, vol. 60, no. 12, pp. 1583-1590, 2009.

[24] W. Jia, Y. Zan, C. Mao et al., "Microstructure evolution and mechanical properties of a lamellar near- $\alpha$ titanium alloy treated by laser shock peening," Vacuum, vol. 184, Article ID 109906, 2021.

[25] N. Xu, J. Shen, W. Xie, L. Wang, D. Wang, and D. Min, "Abnormal distribution of microhardness in tungsten inert gas arc butt-welded AZ61 magnesium alloy plates," Materials Characterization, vol. 61, no. 7, pp. 713-719, 2010.

[26] L. Liu, J. Wang, and J. Zhou, "Effects of laser shock peening on mechanical behaviors and microstructural evolution of brass," Vacuum, vol. 148, pp. 178-183, 2018.

[27] S. Kalainathan and S. Prabhakaran, "Recent development and future perspectives of low energy laser shock peening," Optics \& Laser Technology, vol. 81, pp. 137-144, 2016. 